Articles

\title{
Categorization via movement: the syntax and semantics of ambos ${ }^{1}$ \\ Categorização via movimento: a sintaxe e a semântica de ambos
}

\author{
Alessandro Boechat de Medeiros ${ }^{2}$ \\ Adriana Leitão Martins ${ }^{3}$ \\ Gean Nunes Damulakis ${ }^{4}$
}

\section{ABSTRACT}

In order to explain the syntactic behavior and describe the meaning of the item ambos in Brazilian Portuguese, we propose, assuming the Distributed Morphology framework, (1) that the acategorial root amb-merges, in the syntactic derivation, to a $D$ that moves from inside a full definite $D P$, and this D categorizes the root; (2) that amb- $+D$ merges back to the DP which $D$ was the head of; (3) that the lower copy of $D$ is erased (or becomes

1. We would like to thank the invaluable contributions given by the anonymous reviewers, with their pertinent questions and suggestions, to this work. Thanks also to Filipe Kobayashi, for his careful reading and comments. The remaining mistakes are entirely ours.

2. Universidade Federal do Rio de Janeiro. Rio de Janeiro - Brasil. https:// orcid.org/0000-0001-9925-2643. E-mail: alboechat@1etras.ufrj.br.

3. Universidade Federal do Rio de Janeiro. Rio de Janeiro - Brasil. https:// orcid.org/0000-0003-0510-2586. E-mail: drileitao@yahoo.com.br.

4. Universidade Federal do Rio de Janeiro. Rio de Janeiro - Brasil. https:// orcid.org/0000-0002-3784-9185. E-mail: damulakis@gmail.com. 
invisible) when the derivation reaches $L F$; (4) that the meaning of the combination of $D$ and amb-is defined only if the context provides a unique set of two individuals with the properties defined by the plural NP taken by ambos, and introduces a universal quantification over this set.

Keywords: acategorial roots; syntactic movement; determiner phrases; quantification.

\section{RESUMO}

Para explicar o comportamento sintático e descrever o significado do item ambos em português brasileiro, propomos, assumindo o arcabouço teórico da Morfologia Distribuída, que (1) a raiz acategorial amb-concatena-se, na derivação sintática, com um D que se move de dentro do DP do qual esse Dé o núcleo; (2) amb-+D se concatena de novo com o DP cujo núcleo éo próprio D; (3) a cópia mais baixa de D é apagada (ou se torna invisível) quando a derivação chega a LF; (4) o significado da concatenação de D com amb-é definido somente se o contexto fornece um conjunto único de dois individuos com as propriedades definidas pelo NP plural tomado por ambos, e introduz uma quantificação universal sobre este conjunto.

Palavras-chave: raízes acategoriais; movimento sintático; sintagmas determinantes; quantificação.

\section{Introduction}

The purpose of this paper is to explain the distribution and describe the meaning of the item ambos ("both") in Brazilian Portuguese.

As we will see below, the syntactic behavior of ambos obeys a number of constraints that gives it a special status among nominal quantifiers. We will explain this behavior by proposing that roots can merge (as modifiers) to heads moved from inside the syntactic constituents such heads head. The result of this operation is a categorized root. In the end, the lowest copies of these moved heads must be deleted or become (at least semantically) invisible at LF. More specifically, we will argue that (a) the head D of a DP is sidewardlymoved from inside its DP; (b) the acategorial root of ambos is adjoined 
to $\mathrm{D}$ and $\mathrm{D}$ categorizes it; (c) the determiner $a m b-+\mathrm{D}$ merges to the DP from which D has moved; and (d), for semantic and syntactic reasons, the lowest copy of D is deleted (or becomes invisible) at LF (but not at PF) - but, despite the deletion/invisibility, the already built syntactic structure is preserved. The design of this mechanism, which, we argue, will be able to explain the syntactic and semantic behavior of ambos, will be discussed in the sections below.

The paper has the following organization. In section 1 we discuss some grammatical, semantic and morphological properties of ambos. In section 2 we develop an explanation for the particular syntactic behavior (and for some morphological properties) of the item, comparing it to the item todos. For such an analysis we will assume the Distributed Morphology framework (see Hale \& Marantz, 1993; Marantz, 1997, inter alia). In section 3, we present a semantic definition for ambos, considering all the discussion conducted in section 2 . Section 4 reassesses the proposal and opens for future work.

\section{On the formal and semantic properties of ambos}

In the variety of Brazilian Portuguese spoken by the authors of this paper, the item ambos occurs in a very small number of syntactic contexts (listed below) and has the morphological properties depicted in (f):

(a) It takes determiner phrases, whatever the syntactic function of the determiner phrase (subject, object, and so on) is. The determiner phrase necessarily includes the definite article or a demonstrative determiner - that is, a definite determiner. Even when the determiner phrase includes a possessive pronoun, the presence of the plural definite article is required.

(1) a. Ambos os policiais encontraram Pedro./Pedro encontrou ambos os policiais. Both the policemen found Pedro/Pedro found both the policemen "Both policemen found Pedro"/"Pedro found both policemen".

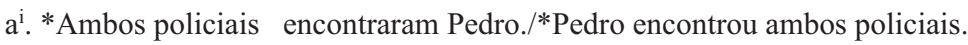
Both policemen found Pedro/ Pedro found both policemen

$\mathrm{a}^{\mathrm{ii}}$. Ambos esses policiais encontraram Pedro

Both these policemen found Pedro

"Both of these policemen found Pedro". 
$\mathrm{a}^{\text {iiii }}$. Ambos os meus filhos jogaram futebol./*Ambos meus filhos jogaram futebol. Both the my sons played soccer/ Both my sons played soccer "Both my sons played soccer"

(b) Ambos may occur as an argument, anaphorically referring to previously mentioned or otherwise easily accessible individuals.

(1) b. Ambos encontraram o Pedro./O Pedro encontrou ambos. Both (of them) met the Pedro/ The Pedro met both (of them)

"Both met Pedro"//Pedro met both."

$\mathrm{b}^{\mathrm{i}}$. [Maria e Joana $]_{\mathrm{i}}$ disseram que ambas $_{\mathrm{i} / \mathrm{j}} \quad$ chegaram. [Maria and Joana $]_{\mathrm{i}}$ said that both ( of them $_{\mathrm{j}}$ ) arrived "Maria and Joana said that both/both of them arrived"

(c) Ambos may occur post-verbally, as if it were stranded. It is worth noting that, when stranded, ambos can be associated to a possessive DP without the definite article, as we see in $\left(1 \mathrm{c}^{\mathrm{i}}\right)$, and with pronouns, as we see in $\left(1 \mathrm{c}^{\mathrm{ii}}\right)$.

(1) c. Os criminosos eram ambos policiais./ Os bandidos foram ambos presos. The criminals were both policemen/ the bandits were both arrested "Both criminals were policemen."/"Both bad guys were arrested."

$c^{i}$. Meus filhos conseguiram ambos um bom emprego.

My sons got both a good job

"Both my sons got a good job."

$\mathrm{c}^{\mathrm{ii}}$. Eles conseguiram ambos um bom emprego.

They got both a good job

"Both of them got a good job."

(d) Ambos may be accompanied by a coordination of two singular definite DPs or two proper names (with pauses around them).

(1) d. Ambos, o policial e o bombeiro, prenderam os assaltantes. Both the policeman and the fireman arrested the robbers. "Both the policeman and the fireman arrested the robbers"

(e) In the presence of ambos, the plural definite article preceding a mass noun necessarily assigns a count interpretation (container, defined quantity or subtype) to the mass noun. 
(1) e. Ambas as águas estavam turvas.

Both the waters were murky.

"Both containers/bottles/glasses of water were murky"

(The relevant comparison must be made between the sentence (1e) and sentences like as águas do rio estavam turvas - the waters of the river were murky -, in which the plural DP as águas has a non-count reading, but indicates a big amount of water.)

(f) Ambos is always plural and agrees in gender with the plural determiner phrase which follows it ${ }^{5}$.

(1) f. Ambos os meninos, *ambos as meninas, *ambo os meninos, *ambo menino.

Both.masc the.masc boys, both.masc the.fem girls, both.sing the.pl boys, both.sing boy.

Turning back to (a), it should be emphasized that ambos cannot be placed before determiner phrases headed by other quantifiers or by the indefinite article; nor does it take bare nouns (at least in the variety spoken by the authors).

(2) *ambos todos os homens, *ambos alguns homens, *ambos uns homens, *ambos homens.

Both all the men, both some men, both a.pl men, both men.

Likewise, it is not allowed that other quantifiers, even the ones which select DPs, take ambos+DP, as in *todos ambos os homens (all both the men).

Ambos behaves like todos (all) in many respects, taking only determiner phrases with the definite article (or demonstrative determiners) and not being licensed to cooccur with most quantifiers, even when stranded:

5. It is also worth noting that the root amb-occurs in other lexical contexts, such as the words ambiguo (ambiguous), ambidestro (ambidextrous), ambivalente (ambivalent) always meaning "two" or "at least two". 
(3) a. [*Alguns homens/uns homens/homens] foram ambos presos pela polícia.

[ Some men/ a.pl men/ men] were both arrested by.the police.

b. ??Todos os bandidos foram ambos presos pela polícia.

All the bandits were both arrested by.the police.

c. ?Os dois homens foram ambos presos pela polícia.

The two men were both arrested by.the police.

"The two men were both arrested by the police"

Though redundant and degraded, expressions such as the one found in (4a) are more acceptable than those found in (2), despite todos (all) should not be, at least apparently, from a logical point of view, incompatible with ambos. Unlike ambos, the quantifier todos does not establish a restriction on the cardinality of the set defined by the plural DP it precedes, as shown in (4b) below, but does not accept ambos $+\mathrm{DP}$ in its sequence, as shown in (4c):

(4) a. ??Ambos os dois bandidos foram presos.

Both the two bandits were arrested.

"Both bad guys were arrested"

b. Todos os dois/três/ cinco/mil bandidos foram presos.

All the two/three/five / one thousand bandits were arrested.

"All the two/three/five... bad guys were arrested"

c. *Todos ambos os bandidos foram presos.

All both the bandits were arrested.

"All the two bad guys were arrested"

There are also order constraints, as seen in (5). But what is really worth noting is that such order constraints depict an asymmetry of distribution between ambos and todos, since the postposition of ambos inside the DP is not allowed (unless with pauses), whereas the postposition of todos is licensed:

(5) a. *os ambos homens; ?*os homens ambos the both men; the men both.

b. *os todos homens; os homens todos the all men; the men all.

Furthermore, although pronouns often have a function similar to that of definite DPs and can perfectly define a set with cardinality compatible with the requirements of ambos, they cannot co-occur with it - except, again, for contexts in which the pronoun is stressed or separated 
from ambos by a comma or pause. Again, compare the examples from (6a) with those from (6b), where the quantifier todos is used.

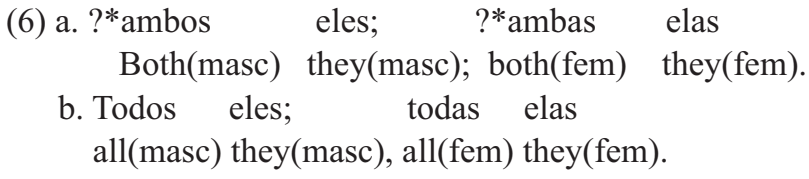

As regards the meaning of ambos, it presupposes the existence of a set, which should be active in the representations of the speakers, containing exactly two individuals or entities with the properties defined by the noun phrase within the DP (except, perhaps, in context (1d) above). So, if someone utters the sentence:

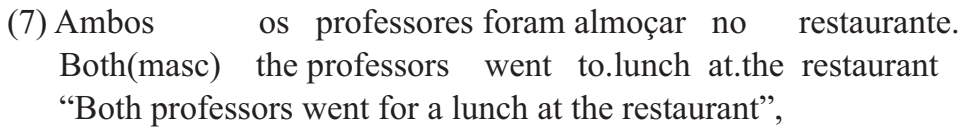

only two of the individuals in the shared context are professors. Then, in a context where one is talking about four individuals, of whom two are professors, one can use the word ambos, as long as the listener knows that there are two (and only two) professors in the context (if she does not know it, she adjusts her beliefs and assumes that two and only two of the four individuals are professors). Thus, in the dialogue below, in which speakers A and B know that Pedro and Maria are professors, but that Joana and Cláudio are not, the use of ambos is fully acceptable.

A: Você não vai acreditar: ontem encontrei o Pedro, a Maria, a Joana e o Cláudio no shopping.

"You won’t believe it: yesterday I met Pedro, Maria, Joana and Cláudio at the mall."

B: Que bacana! E como eles estão?

"That's cool! How are they?"

A: Infelizmente, não pude conversar com todos, pois ambos os professores estavam com pressa e tiveram que sair logo. Mas a Joana e o Cláudio vão bem.

"Unfortunately, I could not talk to all of them, because both the professors were in a hurry and had to leave as soon as we met. But Joana and Cláudio are doing well." 
On the other hand, if three of these individuals, or all, were professors, ambos would not be licensed.

This point is important with respect to the interpretations of the definite DP in comparison to the readings the phrase ambos + DP conveys. Above, we could replace without any loss the expression ambos os professores (both professors) by os professores (the professors), since, supposedly, those who are professors are known by A and B. However, more generally, plural definite DPs do not necessarily refer to all members of the contextually relevant set of individuals with the property defined by their NP in a given context (nor do they introduce a cardinality for that set). In order to understand what we are discussing here, imagine the following situation involving a family with four kids:

After an exhausting day at school, all the brothers arrive home hungry and search something to eat in the refrigerator. They find a pizza. One of them, however, prefers to eat some fruits while the other three devour the pizza. The boys' mother arrives home and sees three of her sons eating the last slices of pizza, while one eats an apple. She then asks the youngest if he also ate the pizza and he says he didn't. The boys' father arrives home, feeling hungry, looks for the pizza in the refrigerator - but does not find it. Then he asks: "Where's the pizza that was in the fridge?" The mother answers:

(8) Os meninos comeram ela toda ${ }^{6}$.

"The boys devoured it."

6. The licensing of the definite article in (8) above might be related to the fact that the constituent os meninos (the boys) is not the topic of the conversation. Curiously, the use of ambos in a context similar to that made up for (8), but in which there were only two boys in the family and the two had eaten the pizza, would not be felicitous, precisely because the constituent os meninos cannot be the topic in such a context. The examples below show it:

A. Cadê a pizza que estava na geladeira?

"Where is the pizza that was in the fridge?"

B. \#Ambos os meninos comeram ela.

"Both the boys have eaten it."

\#Foi comida por ambos os meninos.

"It was eaten by both boys".

That is, ambos is licensed in constituents that are conversational topics - at least typically. 
The answer is adequate, even though not all the individuals in the context that are boys have eaten the pizza. This example shows a use of the definite plural DP that does not necessarily refer to the whole set of contextually relevant boys. But that does not happen with ambos os meninos (both boys), todos os meninos (all boys) or os dois meninos (the two boys). If in the family there were two boys, and only one of them had eaten the pizza, the sentence ambos os meninos comeram a pizza (both boys ate the pizza) would be false (but see fn. 6). That is, like todos, and unlike the DP containing only the definite article, ambos forces the participation of all members of the reference set. This discussion is important for the following reason: we shall further develop the idea that ambos functions as a universal quantifier over a set with cardinality two.

The word ambos introduces the quantity "two", but it is not a synonym of the expression os dois (the two). If ambos were like os dois, it should be expected that ambos would engage in different scope relations with other quantified DPs, as we can see in $(9 \mathrm{c})$, for which there are three clear readings: a distributive, a cumulative and a collective reading. Although collective and cumulative readings are marginally possible, the distributive reading is strongly preferred in sentences such as (9a) below - even in passive sentences such as (9b):

(9) a. Ambos os estudantes fizeram três tarefas.

Both the students did three tasks

"Both students have done three tasks".

b. Três tarefas foram feitas por ambos os estudantes.

Three tasks were done by both the students

"Three tasks have been done by both students".

c. Os dois estudantes fizeram três tarefas.

The two students did three tasks

"The two students have done three tasks".

The same should be said about sentences like (10): the reading in which the weight expressed in the predicate is the sum of the weights of the two candidates is very marginal (if it is acceptable at all); in (10), each candidate will have 120 kilos: 
(10) Ambos os candidatos pesam $120 \mathrm{~kg}^{7}$.

Both the candidates weigh 120 kilos

"Both candidates weigh 120 kilos".

On the other hand, in sentence (11), 120 kilos could be the sum of the weights of the two candidates.

(11) Os dois candidatos pesam $120 \mathrm{~kg}$.

"The two candidates weigh 120 kilos".

As a final remark, it is worth discussing the following point. The Houaiss dictionary (2009) prescriptively states that ambos "cannot be used in allusion to persons or things in opposition". However, it is clear that our use of ambos is not excluded in larger contexts of opposition, as in a well-known motto of a television show: estando bom para ambas as partes... (being it good for both sides...) ${ }^{8}$. But it should be noted that it is not so perfectly acceptable that opposing entities referred to by ambos+DP could engage in reciprocal actions.

Let us imagine that two duelists met for a sword fight at dawn. Though it is implausible, the following sentence (12a) has a clear reading in which each duelist attacked himself, not the other one. For (12b), however, the reciprocal reading, in which they attack one another, is simply direct:

(12) a. ?Ambos os duelistas se atacaram ao amanhecer.

Both the duelists themselves attacked at.the down

"Both duelists attacked themselves/?each other at dawn".

b. Os duelistas se atacaram ao amanhecer.

The duelists themselves attacked at.the dawn

"The duelists attacked each other at dawn"

The remarks in this section open the way for the proposals we will develop in the following pages. In order to explain the facts above,

7. The word juntos (together), though, is able to obliterate the distributive reading of ambos. Then, ambos os candidatos pesam 120kg juntos (both candidates weigh 120 kilos together) has only the cumulative reading. We don't know yet how to explain this fact. 
we will propose that the root $a m b$ - has no grammatical category (see Marantz, 1997) and merges to a D moved from inside a definite DP; the category thus created is then merged again to the original DP. The determiner D categorizes the root and so defines the (phonological and semantic) interpretation of $a m b$-, licensing it in the syntactic structure (Borer, 2009; Embick \& Marantz, 2008; Marantz, 2013).

\section{Ambos and the structure of the determiner phrase}

We saw above that in Brazilian Portuguese (or in the BP variety spoken by the authors at least) the item ambos occurs in determiner phrases whose D hosts definite features; and that the co-occurrence of ambos and the DP has no effect on the distribution of the DP without ambos. That means that ambos does not change the category of the DP it combines with. We can imagine two ways to preserve the category (or the syntactic distribution) of the determiner constituent after ambos: (1) to propose that ambos is a category which is an adjunct to the DP; (2) to argue that it is a category that merges to a definite DP, occupying a position in some sort of expanded determiner phrase structure (a possible "cartography" of the determiner phrase system). However, assuming any of the two options, it would be hard, without unmotivated selectional stipulations, to explain why the word ambos does not behave exactly like items such as todos, as we shall see below (particularly when we consider some restrictions of order we have already pointed out to and will discuss further in this paper). So, we will explore a third possibility and show that it constitutes an interesting way to explain all the properties we discussed so far. This third possibility is schematized in (13) and will be detailed in the next sections:
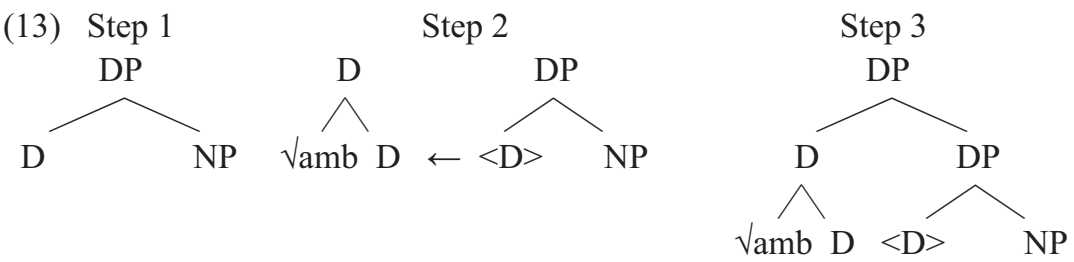

In the proposal sketched in (13) the word ambos is a product of merging $\mathrm{D}$ to the acategorial root $a m b$-, the categorizing $\mathrm{D}$ being 
moved from inside a DP. We will argue that the quantifier todos is merged to the DP as a category already - that is, there is a categorizing morpheme which merges to the root of todos/todo, and then such a category merges to the DP structure. As we saw above, there are some differences between the behavior of todos and ambos. The main differences are: (a) while todos can easily occur immediately after definite DPs (e.g., os homens todos - "the men all"), the occurrence of ambos after DPs is simply unacceptable or, when acceptable, it involves pauses which suggest that we have a different structure; (b) while todos can easily precede a pronoun (todos eles - "all of them"), ambos cannot; and (c) there are singular forms of the quantifier todos, todo (every) and tudo (everything), which may merge to bare nouns and may be even predicates, whereas an equivalent singular form of ambos does not exist.

(14) a. Os estudantes todos entraram na sala.

The students all entered in.the classroom.

"All the students entered the classroom".

b. Os estudantes, ambos, entraram na sala.

The students both entered in.the classroom.

"Both the students entered the classroom"

c. Todos eles entraram na sala.

All they entered in.the classroom.

"All of them entered the classroom".

d. *?Ambos eles entraram na sala.

Both they entered in.the classroom.

"Both of them entered the classroom"

e. Todo estudante visita aquele museu.

Every student visits that museum.

"Every student visits that museum".

f. *Ambo estudante visita aquele museu.

Both(masc, sing) student visits that museum.

One way of explaining the three facts above is to assume that a D categorizes the root $a m b$-, being $\mathrm{D}$ either a phonologically null pronoun directly merged to the root or a definite determiner moved from a complex determiner and merged to the root. At least the last of the options for categorizing a root just discussed is not available to the root of the quantifier todos. Thus, in (14b) (and (1b)), the root $a m b$ - merges to a pronominal $\mathrm{D}$. The result is a pronoun that refers to 
a plural antecedent which is a sum of two and only two entities. (14d) is unacceptable because the pronominal $\mathrm{D}$ is in fact categorizing the root $a m b$-, and there is no place for a complement pronoun. In (14f) there is no determiner (or other categorial head) to categorize the root $a m b-$, violating a condition on the interpretability of roots (Embick \& Marantz, 2008; Marantz, 2013, inter alia). Once something similar to the movement of $\mathrm{D}$ is not necessary for the categorization of the root of todo $(s)$, the quantifier todos is allowed to be stranded in a low position, which generates the order in (14a); and, for the same reason, nothing prevents the occurrence of pronouns after (or before) the quantifier todos, nor the selection of singular bare nouns by the quantifier (14e).

We will present and discuss the proposals in more detail below.

\subsection{The movement of the determiner and its consequences}

Distributed Morphology (henceforth DM) assumes there is a fundamental distinction between roots and the vocabulary related to functional items - the articles, conjunctions, pronouns and affixes in general. For example, the insertion of the functional vocabulary is deterministic (Harley \& Noyer, 1999), and this vocabulary spells-out morphosyntactic features that constitute the building blocks of the syntactic structure, conveying the structural meaning of the sentence, which is strictly compositional (see Marantz, 1997; see also Borer, 2005 for the same idea, though in another framework). Roots are not inserted in the structure the same way; that is, their insertion is not deterministic, and its meaning is negotiated in their immediate syntactic context (Marantz, 2001, 2013; Borer, 2010). This means that pieces of vocabulary that spell-out functional heads will not occupy root positions in sentences, and vice-versa (but see De Belder \& van Craenenbroek, 2015 , for a proposal in which functional vocabulary items can occur in root positions; see also De Belder, 2011 and Creemers at al., 2018, who argue that at least some derivational affixes are roots). Marantz (2013) proposes that roots, in order to become grammatical objects, must merge directly to functional heads in the syntax. Only this way could a root be part of a syntactic structure, and have its meaning and pronunciation defined. We will assume the general ideas of this 
framework, but the discussion below will propose minor changes in it: we will argue that the categorization of a root may take place via syntactic movement, as long as this operation preserves the syntactic structure already built. Let us see how it works.

Suppose the root $a m b$ - is interpretable exclusively either when it merges to certain roots and is categorized in this context, as in ambivalente (ambivalent) and ambidestro (ambidextrous), or when a determiner merges to it to generate the word ambos. Only these contexts should license $a m b$-. We will propose below that the mechanism which generates the item ambos followed by a complex DP involves a movement of the head $\mathrm{D}$ to the root, causing the structure root $+\mathrm{D}$ to become a "word" (a syntactic object), which is a determiner that projects the category $\mathrm{D}$.

Suppose, further, that merging D and the root, via movement, implies the deletion, or at least the (semantic) invisibility, of its lowest copy in LF. Why? The intuition behind such an idea is that if one of the copies is not deleted (or becomes invisible), the same head will be interpreted at both positions, which will create a semantic type mismatch (see section 3 ). The erased/invisible copy must be the lowest one, because if the upper one is erased, the root of ambos remains not categorized, and the structure remains uninterpretable (besides the movement has been vacuous). Notice that the mechanism preserves the structure, keeping a DP - headed by the same head D - as a result. Let us organize the proposal as follows:

1. A definite $\mathrm{D}$ (article or demonstrative pronoun) merges to an NP creating a DP.

2. The root of ambos is selected and D moves (sidewardly - see Nunes (2004)) to it. Roots are modifiers and have no formal features (Marantz, 1997, 2013; Borer, 2005); then $a m b$ - merges to D as an adjunct, not the other way around. Merging $a m b$ - to D provides the root a grammatical status; thus, amb $+\mathrm{D}$ becomes a determiner. $\mathrm{Amb}+\mathrm{D}$ merges (back) to the DP, projecting a DP with the same, original features.

3. In PF, after the spell-out, the lowest copy of the determiner is pronounced in its original position, but not the upper copy, which is 
creating a word with the root. The number and gender marks in ambos are the spell-out of the agreement between the amb+D and the NP it takes as complement ${ }^{9}$.

4. In LF, the lowest copy of D is erased or becomes invisible, but the syntactic structure - the fact that the phrase is a DP - remains "the same".

The representation (15)-(18) shows the steps of the syntactic derivation:

(15) $\left.\left[{ }_{\mathrm{DP}} \mathrm{D}[\mathrm{NP}]\right]\right]$

(16) $\left[{ }_{D}\right.$ amb- $\left.+D\right]\left[\left[_{D P}<D>[N P]\right] \rightarrow\left[{ }_{D P}\left[{ }_{D}\right.\right.\right.$ ambos $]\left[\left[_{D P}\right.\right.$ os [NP $\left.]\right] \rightarrow P F$

(17) $\left.\left[_{D P}\left[D_{D} a m b-+D\right] E_{D P} \mathrm{D}[\mathrm{NP}]\right\}\right]$ (covert syntax)

(18) $\left.\left[_{D P}\left[{ }_{D} a m b-+D\right] f_{D P} \rightarrow[N P]\right\}\right] \rightarrow L F$

The proposal, therefore, argues that (a) the root $a m b$ - is categorized by the head of the DP which ambos modifies; and that (b) the new determiner thus formed $(\mathrm{amb}+\mathrm{D})$ is then internally merged to the root node DP, projecting a DP with the same features.

The mechanism which is being proposed here involves an admittedly heterodox kind of movement, since the category that moves is the one that eventually projects. However, we believe that such a move is a possibility of the system, though at its fringe. In head movements the target category (the category which is not moved) is the one that projects its formal features - the moving category in fact adjoins to the target one. However, in our system, roots have no formal features whatsoever, and, by this reason, cannot project. In fact, for many a scholar (e. g., Marantz, 2013; Borer, 2010), a root is at most able to modify a syntactic template or category/functional head, and so it always adjoins, it is not the target of an adjunction nor project syntactic positions. Therefore, if a head is moved and merges to a root, the result is a syntactic constituent whose category (and other formal

9. One of the reviewers asks us why we are not considering that the definite $\mathrm{D}$ is incorporated to the word ambos. In fact, in some sense of incorporation, we are. We defend here (see below) that the definite D is phonologically null (cf. rule (51a)), and that what we see and pronounce, even in contexts which do not involve the root amb- (or any root at all), are in fact the gender and number marks of the definite article. 
features) are determined by the moving functional head, $\mathrm{D}$ in this case, not by the root, which is in fact adjoined to D.

But why does D move? Our answer is: in order to categorize the root $a m b$-, which otherwise would get no category and thus not be syntactically licensed. Let us suppose that there are two possible ways in which a root can get a category and thus be part of a syntactic structure: either a functional head and a root are merged together directly or a functional head moves from inside a structure, gets a root and "gives it a ride" back into the structure. The second option is restricted to functional heads which, in a specific syntactic derivation, are not categorizing any other root - and that is the case of the head D in the proposed derivation above. Furthermore, the second option is allowed only when the extracted morpheme moves back to the constituent it was the head of - that is, the moved functional head does not become the head of another constituent in the structure. Assuming that these two options of categorizing a root are available, the data (for instance, the presence or not of a determiner like the definite article after ambos and, mainly, the prohibition of the inversion of order between ambos and the DP) will help decide which of the options should be chosen ${ }^{10}$.

But why are pronouns, which are (or include) determiner heads according to the literature (see Abney, 1987, among others), not licensed in the context of ambos in Brazilian Portuguese? One way of dealing with this is to assume that a pronominal $\mathrm{D}$ merges directly to the root of ambos, and since, in this case, there is no lowest copy of D (the pronominal head) there will be no phonological realization of the pronoun after the spell-out (contrary to what happens to articles and demonstrative determiners) This device would explain the pronominal behavior of ambos in the context below.

(19) Dois rapazes entraram na sala. Ambos viram um duende no canto esquerdo. Two boys entered in.the room. Both saw an elf in.the corner left "Two boys got into the room. Both saw an elf in the left corner".

10. Maybe, in the grammar of speakers for whom ambos takes bare NPs (ambos meninos - both boys), D and amb- are merged together directly (the first option above). If our proposal here is on the right track, in such a grammar it is not allowed that ambos be followed by demonstrative determiners. Of course, such a claim needs further investigation, which will be conducted in proper time. 
The derivation in this case would be as follows:

(20) $\left[{ }_{D P} D_{\text {pro }}\right]$

(21) amb-adjoins (merges) to $\left[{ }_{D P} D_{\text {pro }}\right]$

(22) $\left[{ }_{D P}\right.$ amb- $\left.+D_{\text {pro }}\right] \rightarrow\left[{ }_{D P}\right.$ ambos $] \rightarrow P F$

(23) $\left[\mathrm{DP}\right.$ amb- $\left.+\mathrm{D}_{\mathrm{pro}}\right] \rightarrow \mathrm{LF}$

If it is the case that ambos can be a pronoun, we expect it to obey principle B of the binding theory. And that is the case. In sentence (24) below, ambos cannot refer to the subject of the sentence - which c-commands it.

(24) *[Maria e João $]_{\mathrm{i}}$ viram ambos n $_{\mathrm{i}}$ no espelho.

"[Mary and John $]_{\mathrm{i}}$ saw both $_{\mathrm{i}}$ in the mirror".

But it may be bound by something outside the smallest TP that contains it, as the subject of the matrix sentence in (25):

(25) a. [Maria e Joana $]_{\mathrm{i}}$ disseram que eles viram ambas $\mathrm{i}_{\mathrm{ij}}$ no espelho.

"[Maria and Joana $]_{\mathrm{i}}$ said they have seen both ${ }_{\mathrm{i} j \mathrm{j}}$ in the mirror".

We might wonder if, in the cases we are assuming that ambos is pronominal, there occurs in fact a PF ellipsis of a full DP following ambos, as we see in the partial representations (26) and (27):

(26) *[Maria e Joana $]_{\mathrm{i}}$ disseram que eles viram [ambas as moças $]_{\mathrm{i}}$ no espelho. (LF) "[Mary and Joanna $]_{\mathrm{i}}$ said they saw $[\text { both girls }]_{\mathrm{i}}$ in the mirror".

(27) $[\text { Maria e Joana }]_{\mathrm{i}}$ disseram que eles viram [ambas as oças $]_{\mathrm{i}}$ no espelho. (PF)

"[Mary and Joanna $]_{\mathrm{i}}$ said they saw $[\text { both girls }]_{\mathrm{i}}$ in the mirror".

But clearly the coreference should at least be deviant in (26), when compared to (27) - for which, being the DP as moças (the girls) absent, the coreference should be allowed. The reason is obvious: if the DP as moças (the girls) is preserved in the LF representation of the sentence, as in (27), there would be a violation of principle $\mathrm{C}$.

The idea that ambos is, in some contexts, a pronoun may further explain its combination with coordinate structures, such as those found in (1d): being ambos a pronominal element, it can take the reference 
defined by an apposition like the coordination ${ }^{11}$. This way it will not violate the Coordination Structure Constraint, and also explain some prosodic properties of such occurrences (such as the existence of pauses around the coordinated piece). The apposition of ambos after a DP, like the case of os meninos, ambos..., with pauses around ambos, could be explained the same way: a pronominal ambos is maybe adjoined to a definite DP, which triggers the special prosodic properties we see.

In case there is a strong pragmatic reason for pronouncing a pronoun after ambos, which is a very marginal possibility for us, and is more acceptable when the pronoun is not third person, we believe we have, again, a sort of apposition of the pronounced pronoun to the pronominal ambos, yielding some kind of emphasis, or specifying a little more the persons the speaker is talking about - the same way the speaker specifies the persons he is talking about by appending a coordination to the pronominal ambos, as proposed above. The sentence (28) below, found in the internet, shows an example.

(28) Quais são os planos de ambos vocês no geral, para o próximo ano ${ }^{12}$ ?

"What are the plans of both of you for the next year?"

Merging a pronominal $\mathrm{D}$ to the root $a m b$ - also explains the partial acceptance of the diminutive in ambos, ambinhos (both.dim), when ambos is a pronoun, but not when it is followed by a DP headed by an article or by a demonstrative determiner. We know that pronouns have diminutive versions (euzinho, essazinha) ${ }^{13}$, but not articles and demonstrative determiners. Hence the asymmetry between (29a) and (29b-c) below:

11. In sentences like (i) below, we have a pronoun followed by a coordination between pauses:

(i) Eles, o bombeiro e o astronauta, viram um ET ontem à noite.

They, the fireman and the astronaut, saw an ET yesterday to.the night.

"The fireman and the astronaut saw an ET last night."

So, pronouns followed by a coordination (between pauses) is a possibility of the grammar.

12. Example available in: www.riomusicconference.com.br/noticias/the-red-man/. Accessed on 11/27/2018.

13. Euzinho - I.dim.masc; essazinha - this.fem.dim.fem 
(29) a. *Ambinhos

os meninos correram.

Both.dim.masc.pl the boys ran.

b. ??Os meninos, ambinhos, correram.

The boys, both.dim.masc.pl, ran.

"Both boys ran".

c. ?Ambinhos (João e Maria) correram.

Both.dim.masc.pl (João e Maria) ran.

"Both (John and Mary) ran"

The analysis we are developing here does not postulate homophonous items listed in the lexicon, such as a determiner ambos, a pronominal ambos, etc., with very close semantic properties, but different morphosyntactic features. The different "items" are generated in syntax by the same operations, and the differences arise from the different $\mathrm{D}$ heads which can categorize the root $a m b$-.

Our analysis also (a) explains why ambos is not licensed when there is no definite article or a demonstrative determiner merged to NPs with possessive pronouns (example $\left(1 \mathrm{a}^{\mathrm{i}}\right)$ ), and (b) can suggest a possible explanation for why ambos can be left in intermediate position, sometimes by a NP with a possessive pronoun but no determiner and even by a pronoun, as in examples $\left(1 \mathrm{c}^{\mathrm{i}}\right)$ and $\left(1 \mathrm{c}^{\mathrm{ii}}\right)$, repeated below.

(1c $\mathrm{c}^{\mathrm{i}}$ Meus filhos conseguiram ambos um bom emprego.

$$
\text { My sons got both a good job }
$$

"Both my sons got a good job"

(1 $\mathrm{c}^{\mathrm{ii}}$ ) Eles conseguiram ambos um bom emprego.

They got both a good job

"Both of them got a good job."

The explanation for (a) above is the same as we saw before: if there is no article (or demonstrative determiner), $a m b$ - will not be categorized - and uncategorized roots are not allowed to reach LF and PF. The derivation in (30)-(33) shows how we derive ambos os meus filhos (both my children):

(30) $\left[_{\mathrm{DP}} \mathrm{D}\left[\mathrm{NP}\right.\right.$ meus $\left[{ }_{\mathrm{NP}}\right.$ filhos $\left.\left.]\right]\right]$

(31) $[\mathrm{D}$ amb- $+\mathrm{D}]\left[_{\mathrm{DP}}<\mathrm{D}>\left[_{\mathrm{NP}}\right.\right.$ meus $\left[{ }_{\mathrm{NP}}\right.$ filhos $\left.\left.]\right]\right]$

(32) $\left[_{\mathrm{DP}}\left[\mathrm{D}_{\mathrm{D}}\right.\right.$ amb- $\left.+\mathrm{D}\right]\left[_{\mathrm{DP}} \mathrm{D}\left[_{\mathrm{NP}}\right.\right.$ meus $\left[{ }_{\mathrm{NP}}\right.$ filhos $\left.\left.\left.]\right]\right]\right] \rightarrow \mathrm{PF}$

(33) $\left[_{\mathrm{DP}}\left[\mathrm{D}_{\mathrm{D}}\right.\right.$ amb- $\left.+\mathrm{D}\right] \mathrm{E}_{\mathrm{DP}} \mathrm{P}\left[\left[_{\mathrm{NP}}\right.\right.$ meus $\left[_{\mathrm{NP}}\right.$ filhos $\left.\left.\left.]\right]\right\}\right] \rightarrow \mathrm{LF}$ 
On the other hand, for sentences such as $\left(1 c^{\mathrm{i}}\right)$ and $\left(1 \mathrm{c}^{\mathrm{ii}}\right)$ we suggest that in the base position there is an apposition of a pronominal (or anaphoric) ambos to the NP meus filhos (or to a DP os meus filhos) and to the pronoun eles. Then the NP (or the DP) moves from the specifier of $\mathrm{vP}$ or Voice-P to the specifier of TP, leaving a pronominal ambos stranded in base position, as the simplified representation below shows:

(34) $\left[_{T P}[(o s) \text { meus filhos/eles }]_{i}\right.$ conseguiram $\left[\left[_{D P} t_{i}\left[a b_{p o s}\right]\right]\left[_{v P}\right.\right.$ um bom emprego ]]]]

It seems plausible to suppose there is an apposition (maybe a sort of adjunction) of a pronominal (or anaphoric) ambos to a DP (including pronouns) or a NP in the base (spec, vP or Voice-P) position in such cases of stranding because, as we saw above, ambos does not co-occur with pronouns and possessive NPs, like the one in (34), without a determiner. Notice that if we had, in cases of stranding, a structure in which ambos takes a DP as a kind of complement in the DP tree we would not be able to explain satisfactorily why ambos can be stranded by pronouns, for instance ${ }^{14}$, since such a combination is not allowed in other contexts. As another piece of evidence for the proposal above, it seems to us that the diminutive form of stranded ambos is (very) marginally allowed (??as meninas foram ambinhas para a casa da mamãe - the girls went both.dim to their mother's house); as we saw above, the same does not happen when ambos is not a pronoun ( *ambinhas as meninas foram para a casa da mamãe - both.dim the girls went to their mother's house).

The proposal in (15)-(18) also explains the redundant, and marginally acceptable, combination of ambos with os dois NP (the two NP). The derivation is similar to those presented so far, with the movement of $\mathrm{D}$ to the root $a m b$ - and the phonological realization of the article in the original position. Since dois (two) denotes a sum with cardinality at least equal to two, and ambos presupposes a sum with exactly two (see section 3 below), there are neither semantic nor syntactic difficulties in combining ambos and os dois NP, but their combination is deviant because it is redundant.

14. One of the reviewers pointed out that in her dialect ambos cannot co-occur with demonstrative determiners, unless it is stranded. 
All we have proposed so far can also explain the differences between ambos and todos (all). Let us suppose that, unlike ambos in the context of full determiner phrases, the root of todos is categorized via the direct merge of a categorizer to it (or, at least, is not categorized by $\mathrm{D}$ the same way ambos is). It seems plausible that the operator todos has a root, since it occurs in non-functional contexts, as in the adjective total (combination of the root tod- with an adjectivizer morpheme spelled-out by $-a l$ ). In addition to that, some morphological properties of todos indicate that, at least in some contexts, it is a noun or an adjective, since it has a diminutive version and, in the case of tudo (which relates to todo(s) by changing the root vowel height), has a superlative form and can be a predicate, as the following examples show.

(35) a. [T] odinhos os jogos da barbie no site... ${ }^{15}$

All.dim the games of.the Barbie in.the website

"All Barbie's games on the website..."

b. Deus é tudíssimo para $\mathrm{mim}^{16},{ }^{17}$ !

God is all-sup for me

"God is really everything to me".

And since there is no need to move D to the root in order to categorize it, the quantifier todo can directly take a bare noun phrase, as in (14e). The following representation shows it:

(36) $\left[\mathrm{DP}\left[\mathrm{todo}^{18}\right][\mathrm{NP}\right.$ estudante $\left.]\right]$.

15. Available at http://jogosdemeninas.uol.com.br/online/todinhos-os-jogos-da-barbie/. Accessed on 11/27/2018. We also found many occurrences of todinhos eles (all.dim they) searching for it in the internet using Google.

16. Available at $\mathrm{h}$ ttps://www.facebook.com/pages/A-minha-cren $\% \mathrm{C} 3 \% \mathrm{~A} 7 \mathrm{a}-\% \mathrm{C} 3 \% \mathrm{~A} 9$ que-Deus-\%C3\%A9-tud\%C3\%ADssimo-para-mim/157479517635385. Accessed on $11 / 27 / 2018$.

17. It is worth noting that neutral singular forms such as tudo, isso, isto, aquilo have the highest vowels of the Brazilian Portuguese vowel system in their stressed syllables. It seems that neutral demonstratives can be formed by substituting the [-high, -low] stressed vowel of the non-neutral form (todo, esse, este, aquele) for the corresponding [+high, -low] vowel in the vowel system. However, there is no corresponding [+high] vowel in Brazilian Portuguese vowel system for the low central vowel /a/ in the stressed syllable of ambos, as well as no neutral and singular version of the determiner ambos. Notice, further, that there is no semantic constraint precluding the existence of a neutral singular "dual" term; for instance, in German, beides (both) is neutral and singular.

18. Here we are assuming that todo is a determiner, which means that the root $V_{\text {tod- }}$ and $\mathrm{D}$ are merged in syntax, and the determiner thus generated is merged to the NP estudante. 
But why can todos be ordered after the DP, but not ambos, as we can see when comparing os filhos todos (the children all) and * os filhos ambos (the children both)? The answer is as follows. Suppose that, in order to obtain the order DP ambos (or DP todos), there must be a movement of the DP to a position higher than ambos in some sort of extended projection of the DP, call it XP. The movement must happen before the spell-out, for obvious reasons, leaving a trace or copy in the post-ambos position. After the spell-out, there should occur the deletion of the two copies of $\mathbf{D}$ in LF, since, whatever XP is in (39), it should be a generalized quantifier, and therefore, if the two copies of $\mathrm{D}$ are not erased, we will have a non-interpretable structure with at least two determiner heads active for interpretation. However, the deletion of D in the higher copy of the DP would not preserve the structure, converting a DP into an NP in LF, thus removing syntactic structure (or turning it invisible) that would supposedly be required for interpretation and perhaps for the very licensing of the DP in its final position inside $\mathrm{XP}$. The following derivation illustrates it (the constituent in angled brackets is the lowest copy of the moved constituent):

(37) ${ }_{\mathrm{DP}} \mathrm{D}$ [NP filhos]]

(38) $\left[_{\mathrm{DP}}[\mathrm{D}\right.$ amb- $+\mathrm{D}]\left[_{\mathrm{DP}}<\mathrm{D}>\right.$ [NP filhos]]]

(39) $\left[{ }_{\mathrm{XP}}\left[{ }_{\mathrm{DP}}<\mathrm{D}>[\mathrm{NP}\right.\right.$ filhos $\left.]\right] \ldots\left[_{\mathrm{DP}}\left[\left[_{\mathrm{D}}\right.\right.\right.$ amb- $\left.+\mathrm{D}\right]<\left[_{\mathrm{DP}}<\mathrm{D}>[\mathrm{NP}\right.$ filhos $\left.\left.\left.]\right]>\right]\right] \rightarrow$ spellout $\rightarrow\left[{ }_{\mathrm{XP}}\right.$ os filhos ambos]

(40) $\left[_{\mathrm{XP}} \mathrm{E}_{\mathrm{DP}} \mathrm{D}\right.$ [NP filhos] $\ldots\left[_{\mathrm{DP}}[\mathrm{D}\right.$ amb- $+\mathrm{D}]<\mathrm{f}_{\mathrm{DP}} \mathrm{D}$ [NP filhos] $\left.\left.>\right]\right]$

(41) $*\left[_{\mathrm{XP}} \mathrm{E}_{\mathrm{DP}} \mathrm{P}[\mathrm{NP}\right.$ filhos $\left.]\right\} \ldots\left[_{\mathrm{DP}}[\mathrm{D}\right.$ amb- $+\mathrm{D}]<\mathrm{E}_{\mathrm{PP}} \mathrm{P}[\mathrm{NP}$ filhos $\left.\left.] \mathrm{]}\right]\right] \rightarrow \mathrm{LF}$

Assuming that preserving the (LF visible) label is crucial for interpretation, changing the label the way we saw above along the derivation should be heavily precluded.

On the other hand, such a problem does not exist for todos, since the displacement of the DP to a higher position inside the hypothetical XP would keep the structure of the displaced DP intact in the end. Let us see how it works. The step (39) above would be $\left[_{\mathrm{XP}}\left[_{\mathrm{DP}} \mathrm{D}\right.\right.$ [NP filhos]] $\ldots\left[_{\mathrm{DP}}\left[{ }_{\mathrm{aP}}\right.\right.$ todos $\left.^{19}\right]<\left[_{\mathrm{DP}} \mathrm{D}[\mathrm{NP}\right.$ filhos $\left.\left.\left.]\right]>\right]\right] \rightarrow$ spell-out $\rightarrow\left[_{\mathrm{XP}}\right.$ os filhos

As well as other determiners which are not pronouns, todo followed by a bare noun does not accept a diminutive morpheme. 
todos $]$; and in step (41) we would have $\left[_{\mathrm{XP}}\left[{ }_{\mathrm{DP}}\right.\right.$ os filhos $] \ldots\left[_{\mathrm{DP}}\left[_{\mathrm{aP}}\right.\right.$ todos $]$ $<\left[{ }_{\mathrm{DP}}\right.$ os filhos $\left.\left.]>\right]\right] \rightarrow$ LF, which does not involve the undesirable step (40) above. That's why the order DP todos is fully acceptable.

\section{On the meaning of ambos}

Ambos selects semantically plural DPs. The semantics of plurals involves mereological sums (e.g., Farkas \& De Swart (2010); Heim (1994); Link (1983), inter alia), and the atoms of these sums have properties defined by the plural noun phrase selected by $\mathrm{D}$. The presence of a definite $\mathrm{D}$ introduces the presupposition of existence and uniqueness of a given entity or sum of entities.

In section 2 , the determiner $\mathrm{amb}+\mathrm{D}$ was created by moving $\mathrm{D}$ to an acategorial root. Let us suppose that the determiner so created (when $\mathrm{D}$ has the features of a definite article) has the following semantic definition:

(42) $[[\mathrm{amb}-+\mathrm{D}]]=\lambda \mathrm{f}_{<\mathrm{e}, \mathrm{t}}: \exists$ ! sum $\mathrm{X}$ in the relevant context $\mathrm{C}$ such that $\# \mathrm{X}=2$ $\&$ for all atoms $\mathrm{x}$ of $\mathrm{X}, \mathrm{f}(\mathrm{x})=1$ in $\mathrm{C} \cdot \lambda \mathrm{g}_{<\mathrm{e}, \mathrm{t}} \cdot(\forall \mathrm{x})[\mathrm{x}$ is an atom of $\mathrm{X} \& \mathrm{f}(\mathrm{x})$ $=1 \rightarrow \mathrm{g}(\mathrm{x})=1]$.

Roughly speaking, what (42) says is that ambos takes the set of entities in the extension of the plural NP and that each of its members has the properties defined by the predicate of the sentence; says that the context must contain a single set of individuals with the properties defined by the NP and that this set has two (and only two) members. As the LF DP ambos NP is a generalized quantifier, it will have as its domain the set of functions of type $<\mathrm{e}, \mathrm{t}>$. The symbol \# indicates set cardinality.

The definition (42) encodes some contributions of its parts - the root $a m b$ - and $\mathrm{D}$. The contribution of the root is the cardinality of the set in the presupposition part ("\#X=2"). The definite determiner (the definite article) contributes with the uniqueness for the set $\mathrm{X}$ in the presupposition part and the body of the definition itself, which includes

adverbs, only nouns, pronouns and adjectives accept the diminutive affix. However, it is not really important the label of todos for the discussion we are conducting in this section. 
a universal operator. But why is the definite determiner introducing a universal operator? As we have seen from a discussion conducted in section 1, definite determiners merged with plural NPs do not necessarily imply that all the members of the relevant set defined by the plural NP and the context participate on the event denoted by the predicate (see (8) and further discussion in section 1). However, it is clear that the typical (the default, for sure) interpretation of the definite determiner in the context of plural NPs is the one in which the participation of all the members of the set defined by the NP in the context is required. Recall that this maximal participation can be expressed as a universal quantification over the proper variable. Let us assume, then, that the presence of the root $a m b$ - in the immediate syntactic context of the definite $\mathrm{D}$ forces that $\mathrm{D}$ be interpreted as a universal operator (one of its readings, in fact), as laid down in definition (42). Below we shall see other advantages for assuming a universal operator to indicate the maximal participation of the members of the set identified by the NP and made available by the context.

Let us now see how it applies in a concrete example:

(43) Ambos os estudantes entraram na sala
Both the students entered in.the room.
"Both students got into the room"

The noun estudante (student) defines a set of entities with the property of being students. The plural NP estudantes (students) define the set of sums whose atoms have the property of being students. The $a m b+D$ determiner takes the NP estudantes and (1) introduces the presupposition that there is a unique sum of individuals who are students and whose cardinality is two; (2) says that for every individual who is an atom of the unique sum available in the context, the VP predicate (in this case, "got into the room") is true of him/her. Thus, sentence (43) will be true if and only if, for each student available in the context (and the context can only make two students available), this student got into the room. The assumptions above ensure that if there are more or less than two students in the context, the truth-value of the sentence cannot be defined because there is more than one sum with two individuals who are students available in the context, or no sum with two individuals at all. The universal quantifier ensures that 
if the context has exactly two students, but only one (or none) got into the room, the sentence will be false because it will not be true that all students in the context got into the room.

Now one can ask us what differences, if any, between the extensions of os dois NP (the two NP) and ambos NP there might be. In the case of ambos, the incorporation of $\mathrm{D}$ creates a determiner with the extension given in (42) above. In the case of os dois estudantes (the two students), we have the following: the numeral dois takes the NP estudantes and the new NP thus created has as its extension sums of at least two individuals who are students; attaching the article to such an NP delivers a DP denoting the unique sum of two students in the context - it also presupposes that there is a unique sum in the context with the extension of the NP dois estudantes (two students). Furthermore, it implies that the participation of the members of the set defined by the NP (whose cardinality is two) is maximal, whatever the context. Thus, the sentence os dois estudantes entraram na sala (the two students got into the room) will be true if and only if there is a unique sum available in the context whose members are students, whose cardinality is two, and that sum got into the room. So, apparently, there are no differences in the way the world should be in order for the sentences os dois estudantes entraram na sala (the two students got into the room) and ambos os estudantes entraram na sala (both students got into the room) to be true. But let us take a look at the following examples, involving another kind of verbal phrase:

(44) a. Ambos os estudantes pesam $150 \mathrm{~kg}$

Both the students weigh 150 kilos

"Both students weigh 150 kilos".

b. Os dois estudantes pesam $150 \mathrm{~kg}$

The two students weigh 150 kilos.

"The two students weigh 150 kilos".

The sentence (44b) has two possible readings: one in which each student weighs 150 kilos and one in which the total weight of the two students is 150 kilos. The sentence (44a) has only one reading: each student weighs 150 kilos. This indicates that ambos forces a distributive reading which the expression os dois does not. Definition (42) captures this property, stating that the predicate is true of each member of the 
sum of two individuals. That is, while the DP that contains ambos involves a universal quantifier and its semantic definition introduces distributivity, the DP os dois NP, whatever its exact extension, does not necessarily introduce distributivity.

The fact that ambos introduces a universal quantification could be reinforced by the following reasoning. It should be noted that the DP os dois estudantes (the two students) can perfectly be combined with todos generating todos os dois estudantes (all two students). But there is no way we can combine todos with ambos os estudantes (both students) generating something like todos ambos os estudantes. As we hope to have shown above, to simply affirm that todos and ambos compete for the "same position" in the syntax of DPs, and therefore cannot co-occur, does not respond to many questions mentioned in earlier discussion, particularly it does not explain why the two items do not distribute for all the same positions inside DPs, as happens to both and all in English (see fn.21). Thus, if ambos introduces a universal quantifier, as proposed in (42), and if todos also introduces a universal quantifier, the combination of todos and ambos in the same DP would provide two universal operators for the same variable (or, in other words, one of the quantifications would be vacuous, which is forbidden in natural language). The same constraint on merging os dois NP (or os NP) to todos does not exist, since the definite article does not introduce, necessarily, a universal quantification as todos and ambos.

Note, further, that in other languages dual terms are not necessarily precluded to co-occur with universal quantification - as in German, which allows DPs such as alle beide Probleme (all both problems). We believe that the presence of the universal operator in (42) is one of the consequences of the syntactic mechanism of merging a plural D and a root, which applies in Portuguese, but not necessarily in all languages' dual terms. In German, for instance, we have the order article+both+NP (die beide Probleme), which is incompatible with the categorization via movement device exposed above. But further investigation shall be conducted in order to verify this conjecture.

Finally, it is worth clarifying that, from the definitions above, we are able to understand the reason for deleting the lowest copy of D in LF. If the combination of D with the root creates an "item" with the 
formal definition in (42), the semantic type of the members of its domain has to be functions from entities (or sums of entities) to truth-values, not a generalized quantifier, which is not a function whose domain are entities, but a function whose domain are functions. That is, if there is no deletion of the lowest $\mathrm{D}$, ambos would be a determiner having as complement a generalized quantifier - which should not be a kind of function that belongs to the domain of the extension of a determiner-, and the extension of the DP ambos os NP could not be calculated.

\subsection{On the constraints on merging ambos to other determiner phrases and its phonological realization}

Why is there no indefinite ambos? Why is it allowed to merge ambos with demonstratives in ambos esses estudantes entraram na sala (both these students got into the classroom)?

First of all, it should be noted that definiteness is an important (if not the only) property which makes acceptable merging the root ambwith DPs, since demonstratives, like the definite article, are definite, whereas determiners such as uns (a.pl) and alguns (some) are not.

One way of approaching this last point is to conjecture that the meanings of the root $a m b$ - is defined either in the immediate context of $\mathrm{D}$ (any $+\mathrm{D}$ head), that is, the environment we discussed in the previous sections, or when it is a prefix, as in ambidestro (ambidextrous) or ambivalente (ambivalent). Merged to a $\mathrm{D}$, the root introduces an exact cardinality for the set defined by the NP in the relevant context (\#X = 2 in C), which is incompatible with the indeterminacy introduced by indefinite determiners, such as uns and alguns ${ }^{20}$. That is, in the context

20. As pointed out by a reviewer, such a reasoning does not satisfactorily explain why the same meaning (and consequent restriction) is (are) shared by other dual terms in other languages. In English there is no possible combination of both and some; in German, it is also not allowed the combination of beide and einige (the two languages have no plural positive indefinite articles - German has a negative indefinite article, which is not allowed in the same DP as beide as well). But maybe it is a universal property of dual terms that they have a meaning which requires an exact cardinality for the set of individuals referred to in, at least, their presupposition, and $a m b-$, when in the environment of $\mathrm{D}$, becomes a dual term and the $\# X=2$ in $C$ part of (42) is forced into it. Maybe it is related to the informational status of dual terms in languages in general. 
of $\mathrm{D}$, whatever its features, the listed meaning of the root $a m b$ - will include a $\# \mathrm{X}=2$ part, which is incompatible with the uncertainty about the cardinality of the relevant set introduced by an indefinite determiner like uns (eu vi uns cinco meninos lá @ "I saw five boys there, but in fact I'm not so sure about this number"). Notice that pronouns, though they might take the reference of indefinite DPs in discourse, they themselves do not carry an indefinite feature; in fact, they perhaps host a definite feature, so they are not semantically at odds with the listed meaning of the root of ambos.

Once definiteness is compatible with the exact cardinality conveyed by the root in the immediate syntactic environment defined by $\mathrm{D}$, the combination of the root $a m b$ - with demonstrative determiners, which are definite, is possible, and the derivation of ambos esses estudantes, "both (of) these students", would be as the sequence (45)-(48) below depicts. In the derivation, we are abstractly representing the demonstrative determiner by the symbol $\mathrm{D}_{\text {esses }}\left(\mathrm{D}_{\text {these }}\right)$; in addition, we assume that $\mathrm{D}_{\text {esses }}$ brings together features like "definite" and any other hosted by demonstrative pronouns, whatever they $\operatorname{are}^{21}$.

(45) $\left[{ }_{\mathrm{DP}} \mathrm{D}_{\text {esses }}[\mathrm{NP}]\right]$

(46) $\left[\mathrm{DP}\left[\left[_{\mathrm{D}} \mathrm{amb}-+\mathrm{D}_{\text {esses }}\right]\left[_{\mathrm{DP}}<\mathrm{D}_{\text {esses }}>[\mathrm{NP}]\right]\right] \rightarrow\left[_{\mathrm{DP}}\right.\right.$ ambos esses [NP $\left.]\right] \rightarrow \mathrm{PF}$

(47) $\left[_{\mathrm{DP}}\left[\mathrm{D}\right.\right.$ amb- $\left.\left.\left.+\mathrm{D}_{\text {esses }}\right] \mathrm{t}_{\mathrm{DP}} \mathrm{P}_{\text {esses }}[\mathrm{NP}]\right\}\right]$ (covert syntax)

(48) $\left[_{\mathrm{DP}}\left[\mathrm{D}\right.\right.$ amb- $\left.\left.\left.+\mathrm{D}_{\text {esses }}\right] \mathrm{E}_{\mathrm{DP}} \mathrm{D}_{\text {esses }}[\mathrm{NP}]\right]\right] \rightarrow \mathrm{LF}$

21. It is interesting to note as well the parallelism between the dual term of English, both, and its universal quantifier, all. They are allowed to occur with a DP without an intermediate preposition (both the men/all the men); may occur without the presence of the article (both men/all men); can be followed by a prepositional phrase (both of the men/ all of the men); may be preceded by plural pronouns (them both/they all); may precede possessive determiners or genitive forms (both my brothers, both John's brothers/all my brothers, all John's brothers); do not accept other co-occurring quantifier terms (*some both, *both some, *both a(n), *any both, *both any/some/*some all, *all some, *all any/ some) - and therefore all and both have exactly the same distribution in English. These characteristics could be explained if, (i) unlike Portuguese, both has the same "internal" constitution of all - that is, it would be concatenated to DP/NP already categorized (being already a category), not being categorized via movement, as we propose above for ambos and (ii) both, as ambos, says that the relevant set of entities in the context has exact two members, no more, no less (see fn. 20). As we can see, unlike ambos and todos, both and all seem to compete for the same position in the structure of English DPs, and perhaps that is why they cannot cooccur. 
An important consequence of our analysis is that $\mathrm{D}$ will not have any phonological realization when directly merged to the root, even when $\mathrm{D}$ is a demonstrative determiner. Why is that? How can we avoid the generation of ambesses or ambaqueles? Below we propose a tentative solution to this problem.

Recall that in the theoretical framework we are adopting, we have late insertion of the vocabulary, which happens after syntax and some morphophonological operations in the Morphological Structure (henceforth, MS; Halle \& Marantz, 1993), before the derivation reaches PF. Let us suppose tentatively that D may be a complex of nodes in which one node bears the categorial feature $+D$ and the \pm definite features, and another node bundles the specific features which distinguish other determiners (the demonstratives from one another, for instance). Assuming this, we have the following syntactic structure underlying the "word" ambos in demonstrative contexts:

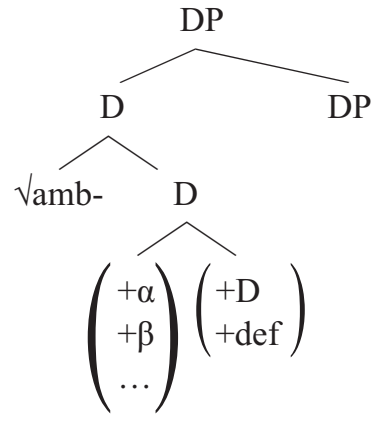

In case $\mathrm{D}$ is the definite article, there is no matrix hosting features such as \pm distal, or pronominal features (the $\pm \alpha, \pm \beta$ features of (49)). But when $\mathrm{D}$ is a demonstrative ${ }^{22}$, $\mathrm{D}$ divides into two bundles of features, as we see in (49) above. Let us suppose, then, that below the upper $\mathrm{D}^{0}$ dominating the root the matrix which does not host features that define the category of the root is simply deleted at MS. That is, there is a morphological deletion rule which operates in such a situation.

22. Perhaps pro is a $\mathrm{D}_{\text {pro }}$ which is not divided into two nodes - maybe it is a phonological zero (rule (51a)) which realizes a bundle of features that assembles + pronominal, $+\mathrm{D}$ and + definite features. We can imagine that pro is directly merged to the root $a m b-$, in order to create pronominal ambos. In this case no deletion rule such as (50) is needed in the derivation of pronominal ambos. 
We might imagine that the deleted matrix introduces a kind of stem (a vocabulary piece that is not a root in DM's sense, because it is deterministically inserted, but is not an affix as well, since it is not a prefix, a suffix or an infix), and such a "stem" is simply precluded in the environment of a root, because such a morphological context should license only affixes.

In (50) we try to formulate such a rule of deletion. In (51) we propose a(n incomplete) list of Vocabulary items for determiners. As we can see from the list in (51), the vocabulary which spells-out the matrices that do not host the $+\mathrm{D}$ feature (see (49) above) seems to be composed of "stems" or "roots" of pronouns, and these "stems" become words with the attachment of theme vowels and number/ gender marks.

(50) $\left[{ }_{D}[+\alpha,+\beta, \ldots][+D,+\right.$ definite $\left.]\right] \rightarrow\left[{ }_{D}+D,+\right.$ definite $] /$ root 23

(51) a. $[+\mathrm{D},+$ definite $] \leftrightarrow \varnothing$

b. $[+\mathrm{D},-$ definite $] \leftrightarrow / \mathrm{uN} /$

c. [-distal] $\leftrightarrow / \mathrm{es} /$

d. $[+$ distal $] \leftrightarrow /$ akel $/$

e. $[+$ pronoun $] \leftrightarrow /$ el $/$ etc.

Thus, the definite article would be phonologically null, and what is in fact pronounced as a definite article in Portuguese are just morphological marks of agreement: gender $(/ \mathrm{o} /$ or $/ \mathrm{a} /)$ and number ( $\varnothing$ or $/ \mathrm{s} /$ ). Then, the item ambos would be the result of combining the following sequence of vocabulary items: $a m b+\varnothing+o+s$.

\section{Conclusions}

This work focused on the particular behavior and meaning of the item ambos, which presents some distributional idiosyncrasies when compared to other quantifiers, particularly todos. In order to deal with

23. One of the reviewers pointed out that in her dialect it is not allowed that ambos be combined with demonstrative determiners (see fn. 14). Perhaps her dialect does not provide the deletion rule (50), and this would simply preclude demonstrative determiners from being root categorizing heads. 
these idiosyncrasies, we have proposed that roots can be categorized via syntactic head movement.

Regarding its meaning, the definition given in (42) and some considerations about the listed encyclopedic entry for the root $a m b$ in the context of D explain the semantic content of ambos and the restrictions it imposes on interpretation, particularly the distributive reading. The definition given in (42) also explains why a reciprocal reading of the reflexive se when ambos is part of its antecedent is, at least, unexpected: if the predicate is true of each atom of the available set, then a reflexive pronoun inside the predicate (see (12a) above) should refer to this atom, not to the other element of the set. We can see more clearly this point if we suppose that the reflexive pronoun se is the realization of the variable bound by the lambda operator inside the predicate. Let us take the example (12a), repeated below:

(52) ?Ambos os duelistas se atacaram ao amanhecer. Both the duelists themselves attacked at.the dawn "Both duelists attacked themselves/?each other at dawn".

Assuming that the predicate se atacaram ao amanhecer is a function of the form $\lambda x$.x attacked $x$ at dawn, and adopting the definition (42), then the expected interpretation for (52) is the one in which for every duelist $x$ of the two available in the context, $x$ attacked $x$ at dawn. The example (12b) does not have the same reading because the reflexive - the variable $\mathrm{x}$ - can take the plural DP (the whole set of duelists) as antecedent; it needs not take as its value each member of the set of duelists available, since the DP os dois duelistas does not introduces a quantification over each member of the set as (52) does.

This research will have another stage in which a comparison will be made among German (beide/beides), English (both) and Portuguese (ambos). The purpose of this research, which is still in its initial stages, is to verify if the proposals contained in this article helps explain the systematic differences between the three languages investigated. Another complementary line of research intends to investigate if the mechanisms developed here could explain the behavior of other determiners, such as algum/alguns (some) in Portuguese. 


\section{References}

ABNEY, S. P. 1987. The English noun phrase in its sentential aspect. $\mathrm{PhD}$ Thesis - Department of Linguistics, Massachusetts Institute of Technology, Cambridge, MA.

BORER, Hagit. 2005. In Name Only: Structuring Sense, Vol. I. Oxford: Oxford University Press.

2009. Roots and Categories. Paper presented at 19th Colloquium on Generative Grammar. University of País Basco, Vitoria-Gasteiz,

CHOMSKY, Noam. 2013. Problems of Projection. Lingua, 130: 33-49.

CREEMERS, Ava; DON, Jon; FENGER, Paula. 2018. Some affixes are roots, others are heads. Natural Language and Linguistic Theory, $36,1: 45-84$.

DE BELDER, Marijke. 2011. Roots and affixes, eliminating lexical categories from syntax. Utrecht: LOT.

DE BELDER, Marijke; van CRAENENBROEK, Jeroen. How to merge a root. Linguistic Inquiry, 46: 625-655.

EMBICK, David; MARANTZ, Alec. 2008. Architecture and blocking. Linguistic Inquiry, 39: 1-53.

FARKAS, Donka; de SWART, Henriëtte. 2010 The semantics and pragmatics of plurals. Semantics \& Pragmatics, v. 3, article 6, 54p.

FERREIRA, Marcelo Barra. Curso de semântica formal. Berlin: Language Science Press, to appear.

HALLE, Morris; MARANTZ, Alec. 1993. "Distributed Morphology and the Pieces of Inflection". In: Hale, Ken \& Samuel Jay Keyser (Eds.). The View from Building 20: Essays in Linguistics in Honor of Sylvain Bromberger. Cambridge MA: the MIT Press: 111-176.

HALLE, Morris; MARANTZ, Alec. 1994. Some key features of Distributed Morphology. In: Carnie, Andrew \& Heidi Harley (Eds.). MIT Working Papers in Linguistics: Papers on phonology and morphology. Cambridge, MA, 21: 275-288.

HARLEY, Heidi; NOYER, Rolf. 1999. Distributed Morphology. Glot International, 4, 4: 3-9.

HEIM, Irene. 1994. Plurals. In: Lecture notes for Advanced Semantics, 1994. Available in: http://www.sfs.uni-tuebingen.de/ astechow/ Lehre/SS08/Heim_Plurals\%20'94.pdf. Accessed in: 04/13/2018.

HEIM, Irene; KRATZER, Angelika. 1998. Semantics in Generative Grammar. Blackwell Textbooks in Linguistics. Oxford: Blackwell Publisher.

HOUAISS, Antônio; VILLAR, Mario de Salles. 2009. Dicionário Houaiss de Língua Portuguesa. Elaborado pelo Instituto Antônio Houaiss de 
Lexicografia e Banco de Dados da Língua Portuguesa S/C Ltda. Rio de Janeiro: Objetiva.

LINK, Godehard. 1983. The logical analysis of plural and mass nouns: a lattice-theoretic approach. Reprinted in: Portner, Paul \& Barbara H. Partee (Eds.). 2002. Formal Semantics: the essential readings. Blackwell Publishing: 127-147.

MARANTZ, Alec. 1997. No escape from syntax: don't try morphological analysis in the privacy of your own lexicon. In: Dimitriadis, A. et al. (Eds.). University of Pennsylvania Working Papers in Linguistics: Proceedings of the $21^{\text {st }}$ Annual Penn Linguistics Colloquium, 4, 2: 201-225.

MARANTZ, Alec. 2001. Words. Massachusetts Institute of Technology (MIT), Cambridge, MA, manuscript

MARANTZ, Alec. 2013. Locality Domains for Contextual Allomorphy across the Interfaces. In: Matushansky, Ora \& Alec Marantz. (Eds.). Distributed Morphology Today: Morphemes for Morris Halle. Cambridge, MA: The MIT Press: 95-115.

NUNES, Jairo. 2004. Linearization of Chains and Sideward Movement. Cambridge, MA: The MIT press.

TRAVIS, Lisa. 1984. Parameters and Effects of Word Order Variation. 1984. PhD Thesis - Department of Linguistics, Massachusetts Institute of Technology, Cambridge, MA.

Recebido em: 10/12/2018

Aprovado em: 17/04/2020 